\title{
Macropinocytosis and TAK1 mediate anti-inflammatory to pro-inflammatory macrophage differentiation by HIV-1 Nef
}

\author{
M Hashimoto ${ }^{1}$, H Nasser ${ }^{1}$, T Chihara ${ }^{1}$ and S Suzu ${ }^{*, 1}$
}

Macrophages (MT) are functionally classified into two types, anti-inflammatory M2 and pro-inflammatory M1. Importantly, we recently revealed that soluble HIV-1 proteins, particularly the pathogenetic protein Nef, preferentially activate M2-M $\Phi$ and drive them towards an M1-like $M \Phi$, which might explain the sustained immune activation seen in HIV-1-infected patients. Here, we show that the preferential effect of Nef on M2-M $\Phi$ is mediated by TAK1 (TGF- $\beta$-activated kinase 1 ) and macropinocytosis. As with MAP kinases and NF- $\kappa$ B pathway, Nef markedly activated TAK1 in M-CSF-derived M2-M $\Phi$ but not in GM-CSF-derived M1-M $\Phi$. Two Nef mutants, which were unable to activate MAP kinases and NF- $\kappa$ B pathway, failed to activate TAK1. Indeed, the TAK1 inhibitor 5Z-7-oxozeaenol as well as the ectopic expression of a dominant-negative mutant of TAK1 or TRAF2, an upstream molecule of TAK1, inhibited Nef-induced signaling activation and M1-like phenotypic differentiation of M2-M $\Phi$. Meanwhile, the preferential effect of Nef on M2-M $\Phi$ correlated with the fact the Nef entered M2-M $\Phi$ more efficiently than M1-M $\Phi$. Importantly, the macropinosome formation inhibitor EIPA completely blocked the internalization of Nef into M2-M $\Phi$. Because the macropinocytosis activity of $\mathrm{M} 2-\mathrm{M} \Phi$ was higher than that of $\mathrm{M} 1-\mathrm{M} \Phi$, our findings indicate that Nef enters $\mathrm{M} 2-\mathrm{M} \Phi$ efficiently by exploiting their higher macropinocytosis activity and drives them towards M1-like $M \Phi$ by activating TAK1.

Cell Death and Disease (2014) 5, e1267; doi:10.1038/cddis.2014.233; published online 29 May 2014

Subject Category: Immunity

Macrophages $(\mathrm{M} \Phi)$, an essential component of the innate immune system found in all tissues, have an important role in inflammation and host defense. ${ }^{1}$ Functionally, $\mathrm{M} \Phi$ are classified into two types, classically activated $\mathrm{M} 1-\mathrm{M} \Phi$ and alternatively activated $\mathrm{M} 2-\mathrm{M} \Phi .^{2} \mathrm{M} 1-\mathrm{M} \Phi$ are characterized by the production of high levels of pro-inflammatory cytokines and chemokines. In contrast, $\mathrm{M} 2-\mathrm{M} \Phi$ are characterized by efficient phagocytic activity and high scavenger receptor expression. $\mathrm{M} \Phi$ can undergo pro-inflammatory $\mathrm{M} 1$ or antiinflammatory $\mathrm{M} 2$ activation in response to various signals, but flexibility is a key feature of $\mathrm{M} \Phi$ activation, and the phenotypes of polarized $\mathrm{M} 1$ - and $\mathrm{M} 2-\mathrm{M} \Phi$ can be reversed to some extent. ${ }^{2}$

HIV-1 infection is characterized by chronic immune activation and inflammation, which is a significant predictor of HIV-1 disease progression. ${ }^{3,4} \mathrm{M} \Phi$, one of the major targets of HIV-1, might contribute to this process, as the pathologies of many diseases are often associated with changes in the balance between $\mathrm{M} 1-\mathrm{M} \Phi$, which are implicated in initiating and sustaining inflammation, and $\mathrm{M} 2-\mathrm{M} \Phi$, which are involved in the resolution of chronic inflammation. ${ }^{2}$ Indeed, in vitro studies have shown that HIV-1 infection drives $\mathrm{M} \Phi$ towards an $\mathrm{M} 1$-like phenotype. ${ }^{5-7}$ Interestingly, soluble HIV-1 proteins, such as the envelope glycoprotein gp120, the trans-activating protein Tat, and the pathogenetic protein Nef, can activate even uninfected $\mathrm{M} \Phi .{ }^{8}$ These viral proteins are present in the sera of
HIV-1-infected patients and might be released by infected and apoptotic cells. ${ }^{8,9}$ Among them, Nef has been shown to activate MAP kinases, NF- $\kappa \mathrm{B}$, and Stat pathways in uninfected $\mathrm{M} \Phi$, resulting in the increased production of a number of pro-inflammatory cytokines and chemokines, including IL- $1 \beta$, IL-6, TNF- $\alpha$, MIP- $1 \alpha$, and MIP- $1 \beta .^{10-13}$

We recently revealed that soluble HIV-1 proteins, particularly Nef, preferentially targeted $\mathrm{M} 2-\mathrm{M} \Phi$, rather than $\mathrm{M} 1-\mathrm{M} \Phi .^{14}$ It is well established that GM-CSF and M-CSF induce the production of $\mathrm{M} 1$ and $\mathrm{M} 2-\mathrm{M} \Phi$, respectively. ${ }^{15-17}$ We demonstrated that MAP kinases and NF- $\kappa$ B pathway were markedly activated by Nef in M-CSF-derived M2-M $\Phi$ but not in GM-CSF-derived M1-M $\Phi .{ }^{14}$ We also demonstrated that Nef stimulated the production of a number of pro-inflammatory cytokines/chemokines in $\mathrm{M} 2-\mathrm{M} \Phi$ but reduced their expression of the scavenger receptor CD163 and phagocytic activity, ${ }^{14}$ which are characteristic markers of $\mathrm{M} 2-\mathrm{M} \Phi,{ }^{2}$ indicating that Nef drives an M2- to M1-like phenotypic differentiation. The study outlines a possible mechanism by which Nef efficiently induces the development of pro-inflammatory $\mathrm{M} \Phi$ population, because the development of most tissue $M \Phi$ depends on M-CSF and its receptor, ${ }^{18,19}$ which is an essential axis for the anti-inflammatory $\mathrm{M} 2-\mathrm{M} \Phi$ phenotype. ${ }^{15-17}$

Soluble Nef proteins have been shown to directly enter $\mathrm{M} \Phi$ and thereby induce signaling activation. ${ }^{8,12}$ Indeed, in line with

\footnotetext{
${ }^{1}$ Center for AIDS Research, International Research Center for Medical Sciences (IRCMS), Kumamoto University, Kumamoto, Japan

${ }^{*}$ Corresponding author: S Suzu, Center for AIDS Research, International Research Center for Medical Sciences (IRCMS), Kumamoto University, Honjo 2-2-1, Kumamoto-city, Kumamoto 860-0811, Japan. Tel: +81 96373 6828; Fax: +81 96373 6825; E-mail: ssuzu06@ kumamoto-u.ac.jp

Keywords: macrophages; macropinocytosis; TAK1; M-CSF; GM-CSF; Nef

Abbreviations: DMSO, dimethyl sulfoxide; DN, dominant-negative; EIPA, 5-(N-ethyl- $N$-isopropyl)amiloride; M $\Phi$, macrophages; TAK1, TGF- $\beta$-activated kinase 1; TRAF2, TNF receptor-associated factor 2; WT, wild-type

Received 24.2.14; revised 23.3.14; accepted 28.3.14; Edited by G Raschellà
} 
its preferential effect on $\mathrm{M} 2-\mathrm{M} \Phi$, we demonstrated that Nef entered $\mathrm{M} 2-\mathrm{M} \Phi$ more rapidly and efficiently than $\mathrm{M} 1-\mathrm{M} \Phi .^{14}$ However, the precise mechanism by which Nef enters $M \Phi$, particularly $\mathrm{M} 2-\mathrm{M} \Phi$ more efficiently, is poorly understood. It also remains to be determined how Nef strongly activates both MAP kinases and NF- $\kappa$ B pathway and induces an M2- to M1like phenotypic differentiation. Our previous pharmacological inhibition analysis suggests that various kinases that have been reported to be activated by Nef, including Hck, PI3-kinase, and p21-activated kinase, ${ }^{20-22}$ are not involved in the preferential effect of Nef on $\mathrm{M} 2-\mathrm{M} \Phi .{ }^{14}$ Here, we provide the first evidence that macropinocytosis and TAK1 (TGF- $\beta$ activated kinase 1, also known as MAP3K7) mediate the anti-inflammatory to pro-inflammatory $M \Phi$ differentiation by the HIV-1 pathogenetic protein Nef.

\section{Results}

Nef-induced strong activation of MAP kinases and $\mathrm{NF}-\kappa \mathrm{B}$ pathway in M2-M $\Phi$ is mediated by TAK1. As reported previously, ${ }^{14}$ the recombinant Nef proteins strongly activated MAP kinases (p38, JNK, and ERK) and NF- $\kappa$ B pathway (IKK $\alpha / \beta$ phosphorylation and $I \kappa B$ degradation) in M-CSF-derived M2 but only weakly activated them in GM-CSF-derived M1-M $\Phi$ (Figure 1a). Our previous study showed that the activation of $\mathrm{p} 38$ in $\mathrm{M} 2-\mathrm{M} \Phi$ was detectable at a minimum Nef concentration of $3 \mathrm{ng} / \mathrm{ml},{ }^{14}$ which is comparable to the concentration of Nef seen in patients' sera $(1-10 \mathrm{ng} / \mathrm{ml}),{ }^{9}$ and the observed effect was specific to Nef, because the Nef preparation failed to activate p38 when it was immune-depleted with anti-Nef antibodies. ${ }^{14}$ In this study, we initially found that TAK1, a MAP kinase kinase kinase, ${ }^{23}$ was also strongly activated by Nef in $\mathrm{M} 2-\mathrm{M} \Phi$, but not in $\mathrm{M} 1-\mathrm{M} \Phi$ (Figure 1a). The slowly migrating TAK1 on SDS-PAGE was shown to represent a phosphorylated and activated form, ${ }^{24}$ which was detected in Nef-treated M2-M $\Phi$ (total TAK1 blot). The activation of TAK1 was further confirmed using an antibody specific to phosphorylated TAK1 ( $p$-TAK1 blot). In the previous study, ${ }^{14}$ we used three Nef mutants, G2A, AxxA, and LL/AA. Among them, two

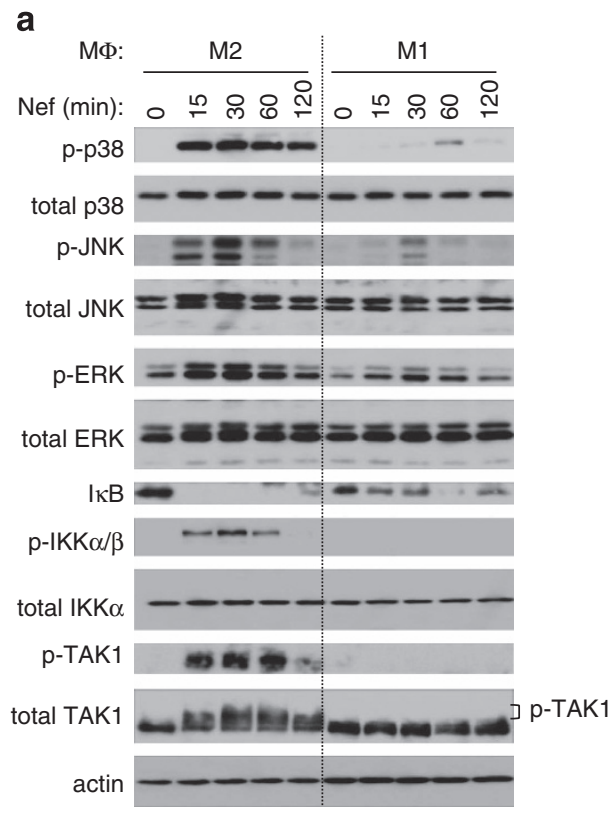

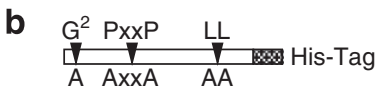

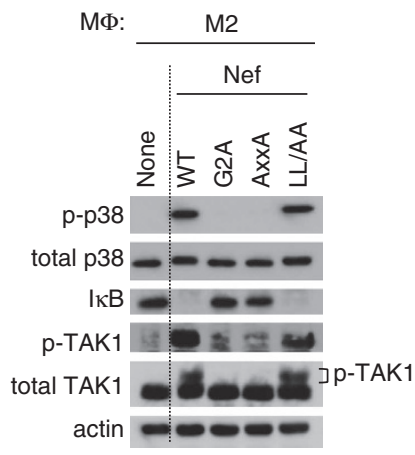

C

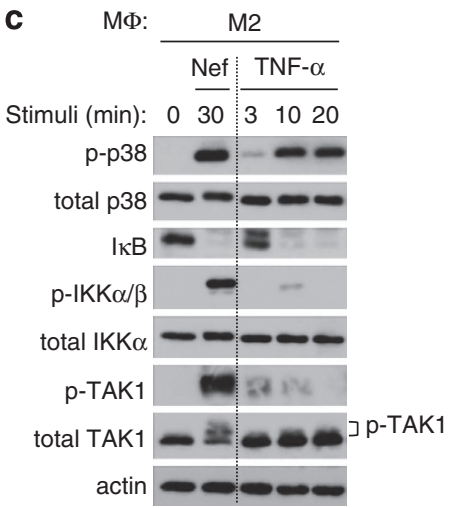

Figure 1 The differential Nef-induced activation of MAP kinases, NF- $\kappa$ B pathway, and TAK1 between M2 and M1-M $\Phi$. (a) M $\Phi$ were obtained by culturing peripheral blood monocytes from a single donor for 5 days with $100 \mathrm{ng} / \mathrm{ml}$ macrophages colony-stimulating factor (M-CSF; M2) or $10 \mathrm{ng} / \mathrm{ml}$ granulocyte-macrophages colony-stimulating factor (GM-CSF; M1), stimulated with Nef (100 ng/ml) for the indicated periods ( $\mathrm{min})$ and analyzed by western blotting using the indicated antibodies. p-p38: phospho-p38, p-JNK: phospho-JNK, p-ERK: phospho-ERK, p-IKK $\alpha / \beta$ : phospho-IKK $\alpha / \beta$, p-TAK1: phospho-TAK1. The slowly migrating TAK1 in total TAK1 blots represents the phosphorylated and activated form (p-TAK1). (b) The His-tagged Nef mutants used (G2A, AxxA, and LL/AA) are shown schematically. To verify that the concentrations of these Nef preparations were equivalent, samples of these preparations with identical volumes were analyzed by western blotting using anti-His-tag antibodies (data not shown). M2-M $\Phi$ were stimulated with $100 \mathrm{ng} / \mathrm{ml}$ WT Nef or the indicated Nef mutants for $30 \mathrm{~min}$ and then analyzed by western blotting using the indicated antibodies. (c) M2-M $\Phi$ were stimulated with Nef $(100 \mathrm{ng} / \mathrm{ml})$ or tumor necrosis factor- $\alpha(10 \mathrm{ng} / \mathrm{ml})$ for the indicated periods $(\mathrm{min})$ and then analyzed by western blotting using the indicated antibodies. (a-c) The actin blot is a loading control. Experiments were repeated with $M \Phi$ obtained from different donors, and the data shown are representative of three independent experiments with similar results. ERK, extracellular signal-regulated kinase; IKK, inhibitor-kB kinase; JNK, c-Jun N-terminal kinase 
mutants, G2A, which lacks a myristoylation site, and AxxA, which carries a mutation in its proline-rich PxxP motif, 25,26 failed to activate MAP kinases and NF- $\kappa$ B pathway. ${ }^{14}$ As shown in Figure $1 \mathrm{~b}$, these mutants also failed to activate TAK1, even when they were added to $\mathrm{M} 2-\mathrm{M} \Phi$. In contrast, the LL/AA mutant, which carries a mutation in its di-leucine motif, ${ }^{25,26}$ activated MAP kinases, NF- $\kappa$ B pathway, ${ }^{14}$ and also TAK1 (Figure 1b). We then compared the ability of Nef to activate TAK1 with that of TNF- $\alpha$, which is known to activate TAK1. ${ }^{23}$ As shown in Figure 1c, Nef activated p38, $\mathrm{IKK} \alpha / \beta$, and also TAK1 more strongly than TNF- $\alpha$.

TAK1 was originally identified as a kinase that is involved in TGF- $\beta$ signaling. ${ }^{27}$ Interestingly, TAK1 also functions as an upstream signaling molecule of MAP kinases and NF- $\kappa \mathrm{B}$ pathway in IL-1 signaling pathways. ${ }^{28}$ Thus, we next investigated whether TAK1 mediates the Nef-induced activation of MAP kinases and NF- $\kappa \mathrm{B}$ pathway in $\mathrm{M} 2-\mathrm{M} \Phi$ using 5Z-7-oxozeaenol, a selective inhibitor of TAK1. ${ }^{29,30} \mathrm{We}$ found that the pretreatment of $\mathrm{M} 2-\mathrm{M} \Phi$ with $5 Z$-7-oxozeaenol inhibited the Nef-induced activation of MAP kinases and $\mathrm{NF}-\kappa \mathrm{B}$ pathway in a concentration-dependent manner (Figure 2a). The inhibitory effects of 5Z-7-oxozeaenol on the activation of $\mathrm{p} 38, \mathrm{ERK}, \mathrm{JNK}, \mathrm{IKK} \alpha / \beta$, and $\mathrm{TAK} 1$ were detectable at concentrations of $0.1-0.2 \mu \mathrm{M}$, which were used in previous studies, ${ }^{29,30}$ although higher concentrations
( $>0.5 \mu \mathrm{M}$ ) were required for the inhibition of $\mathrm{I} \kappa \mathrm{B}$ degradation (Figure 2a). Nef also activates Stat family proteins in $\mathrm{M} \Phi,{ }^{14}$ which appears to be initiated by the activation of MAP kinases and/or NF- $\kappa$ B pathway followed by the enhanced production of pro-inflammatory cytokines and chemokines. ${ }^{10,12}$ Indeed, the activation of Stat1 and Stat3 in Nef-treated M2-M $\Phi$ showed delayed kinetics (detectable at 2 and $4 \mathrm{~h}$, respectively) compared with that of p38 activation (detectable within $1 \mathrm{~h})$, and $5 \mathrm{Z}-7$-oxozeaenol $(0.3 \mu \mathrm{M})$ also inhibited the Nef-induced activation of Stat1 and Stat3 (Figure 2b). The inhibitory effect was specific to Nef, because 5Z-7oxozeaenol did not inhibit GM-CSF-induced activation of Stat1 and Stat5 in M2-M $\Phi$ (Figure 2c).

Nef-induced weak activation of MAP kinases and NF- $\kappa$ B pathway in $M 1-M \Phi$ is also mediated by TAK1. Although the precise mechanism is poorly understood, soluble Nef has been shown to enter $\mathrm{M} \Phi .{ }^{13,31}$ Indeed, our previous study showed that FITC-labeled Nef entered $\mathrm{M} 1-\mathrm{M} \Phi$ less efficiently than it entered $\mathrm{M} 2-\mathrm{M} \Phi,{ }^{14}$ which accounted for the weak signaling activation induced in $\mathrm{M} 1-\mathrm{M} \Phi$ by Nef (see Figure 1a). Interestingly, this was the case even when $\mathrm{M} 2-\mathrm{M} \Phi$ were treated with IL-32 (Figures $3 \mathrm{a}$ and b), a recently identified cytokine that supports pro-inflammatory $\mathrm{M} \Phi$ differentiation. $^{32}$ FITC-labeled Nef entered IL-32-treated
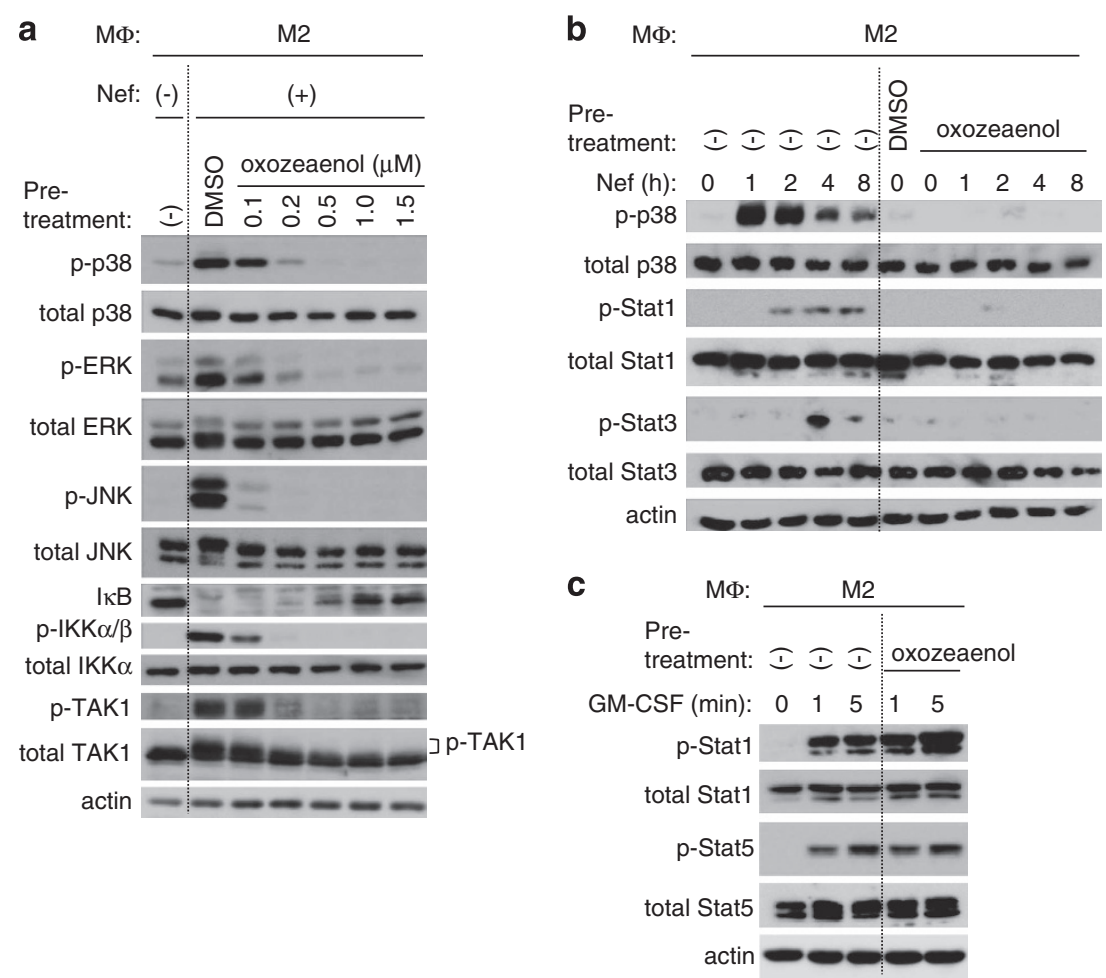

Figure 2 The effect of TAK1 inhibitor 5Z-7-oxozeaenol on the Nef-induced signaling activation in M2-M $\Phi$. (a) M2-M $\Phi$ were left untreated ( - ) or pretreated for $1 \mathrm{~h}$ with DMSO or $5 Z-7-0 x$ zzeaenol at the concentrations indicated $(\mu \mathrm{M})$. Then, the $\mathrm{M} \Phi$ were left untreated $(-)$ or stimulated with Nef $(100 \mathrm{ng} / \mathrm{ml})$ for $30 \mathrm{~min}$ and then analyzed by western blotting using the indicated antibodies. (b) M2-M $\Phi$ were left untreated $(-)$ or pretreated for $1 \mathrm{~h}$ with DMSO or $5 \mathrm{Z}-7-0 x 0 z$ eaenol $(0.3 \mu \mathrm{M})$. Then, the M $\mathrm{M}$ were left untreated or stimulated with Nef $(100 \mathrm{ng} / \mathrm{ml})$ for the indicated periods (h) and analyzed by western blotting using the indicated antibodies. (c) M2-M $\Phi$ were left untreated ( - ) or preincubated for $1 \mathrm{~h}$ with DMSO or $5 Z-7-0 x$ ozeaenol $(0.3 \mu \mathrm{M})$. Then, the $\mathrm{M} \Phi$ were left untreated or stimulated with granulocyte-macrophages colony-stimulating factor $(\mathrm{GM}-\mathrm{CSF} ; 10 \mathrm{ng} / \mathrm{ml})$ for the indicated periods ( $\mathrm{min}$ ) and analyzed by western blotting using the indicated antibodies. p-Stat1: phospho-Stat1, p-Stat3: phospho-Stat3, p-Stat5: phospho-Stat5. (a-c) The actin blot is a loading control. Experiments were repeated with M2-M $\Phi$ obtained from different donors, and the data shown are representative of three independent experiments with similar results. ERK, extracellular signal-regulated kinase; IKK, inhibitor-kB kinase; JNK, c-Jun N-terminal kinase; Stat, signal transducer and activator of transcription factor 


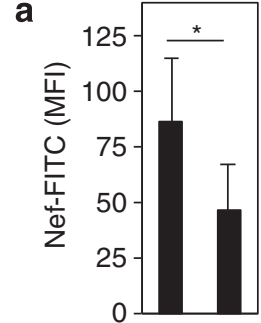

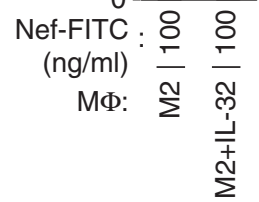

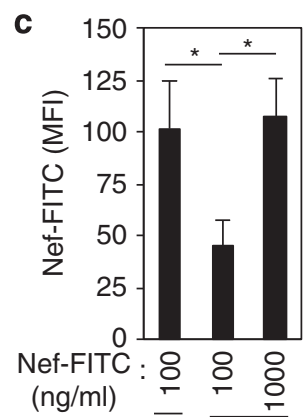

$\mathrm{M} \Phi: \overline{\mathrm{M} 2} \overline{\mathrm{M} 1}$
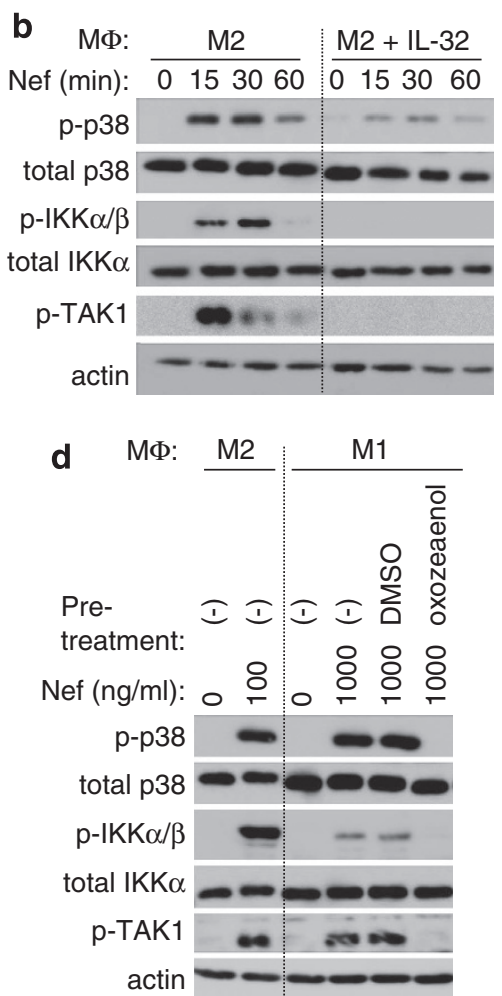

Figure 3 The internalization of FITC (fluorescein isothiocyanate)-labeled Nef and signaling activation in interleukin (IL)-32-treated M2-M $\Phi$ and the effect of 5Z-7oxozeaenol on the signaling activation induced in $\mathrm{M} 1-\mathrm{M} \Phi$ by a high concentration of Nef. (a) $M \Phi$ were obtained by culturing peripheral blood monocytes for 5 days with $100 \mathrm{ng} / \mathrm{ml}$ macrophages colony-stimulating factor (M-CSF; M2). The resultant M $\Phi$ were left untreated or treated with IL-32 (100 ng/ml) for another 2 days (M2 + IL-32). These $M \Phi$ were incubated with FITC-labeled Nef $(100 \mathrm{ng} / \mathrm{ml})$ for $60 \mathrm{~min}$ at $37^{\circ} \mathrm{C}$, detached from the wells using trypsin after extensive washing with phosphatebuffered saline, and analyzed for internalized Nef by flow cytometry. The mean fluorescence intensity (MFI) of the internalized FITC-labeled Nef was analyzed, and the results for $M \Phi$ obtained from three different donors are summarized. ${ }^{*} P<0.05$. (b) M2-M $\Phi$ and IL-32-treated M2-M $\Phi$ were prepared as in panel (a), stimulated with Nef $(100 \mathrm{ng} / \mathrm{ml})$ for the indicated periods $(\mathrm{min})$, and then analyzed by western blotting using the indicated antibodies. (c) $M \Phi$ were obtained by culturing peripheral blood monocytes from a single donor for 5 days with $100 \mathrm{ng} / \mathrm{ml} \mathrm{M-CSF} \mathrm{(M2)} \mathrm{or}$ $10 \mathrm{ng} / \mathrm{ml}$ granulocyte-macrophages colony-stimulating factor (M1). The resultant $\mathrm{M} \Phi$ were then incubated with FITC-labeled Nef (100 or $1000 \mathrm{ng} / \mathrm{ml}$ ) for $60 \mathrm{~min}$ at $37^{\circ} \mathrm{C}$ and analyzed for the internalized Nef by flow cytometry as in panel (a). The MFI of the internalized FITC-labeled Nef was analyzed, and the results for $M \Phi$ obtained from three different donors are summarized. ${ }^{*} P<0.05$. (d) $\mathrm{M} 2-\mathrm{M} \Phi$ and $\mathrm{M} 1-\mathrm{M} \Phi$ were prepared as in panel (c). The resultant $\mathrm{M} 2-\mathrm{M} \Phi$ were left untreated or stimulated with Nef $(100 \mathrm{ng} / \mathrm{ml})$ for $30 \mathrm{~min}$. The $\mathrm{M} 1-\mathrm{M} \Phi$ were left untreated $(-)$ or pretreated for $1 \mathrm{~h}$ with DMSO or $5 \mathrm{Z}-7-0 x$ ozeaenol $(0.3 \mu \mathrm{M})$. Then, the M1-M $\Phi$ were left untreated or stimulated with Nef $(1000 \mathrm{ng} / \mathrm{ml})$ for $30 \mathrm{~min}$ and analyzed by western blotting using the indicated antibodies. ( $b$ and $\mathbf{d}$ ) The actin blot is a loading control. Experiments were repeated with $\mathrm{M} \Phi$ obtained from different donors, and the data shown are representative of three independent experiments with similar results. IKK, inhibitor- $\mathrm{KB}$ kinase

$\mathrm{M} 2-\mathrm{M} \Phi$ less efficiently that it entered untreated $\mathrm{M} 2-\mathrm{M} \Phi$ (Figure 3a), which was consistent with the weak activation of $\mathrm{p} 38, \mathrm{IKK} \alpha / \beta$, and TAK1 by Nef in IL-32-treated $\mathrm{M} 2-\mathrm{M} \Phi$ (Figure $3 b$ ). Based on the result, we next investigated whether the Nef-induced weak activation of MAP kinases and $\mathrm{NF}-\kappa \mathrm{B}$ pathway in $\mathrm{M} 1-\mathrm{M} \Phi$ is also mediated by TAK1. To equalize the amount of Nef that entered the $\mathrm{M} \Phi, \mathrm{M} 2$ and
$\mathrm{M} 1-\mathrm{M} \Phi$ were incubated with 100 and $1000 \mathrm{ng} / \mathrm{ml}$ Nef, respectively (Figure $3 \mathrm{c}$ ). Under these conditions, the high concentration $(1000 \mathrm{ng} / \mathrm{ml})$ of Nef induced the activation of p38 as well as TAK1 in M1-M $\Phi$ at a level comparable to that seen in $\mathrm{M} 2-\mathrm{M} \Phi$ treated with 10-fold lower concentration $(100 \mathrm{ng} / \mathrm{ml})$ of Nef, and the activation of both p38 and IKK $\alpha / \beta$ induced in $\mathrm{M} 1-\mathrm{M} \Phi$ by the high concentration of Nef was completely inhibited by $0.3 \mu \mathrm{M} 5 Z$-7-oxozeaenol (Figure 3d). Thus, although $\mathrm{M} 1-\mathrm{M} \Phi$ were less sensitive to Nef stimulation than $\mathrm{M} 2-\mathrm{M} \Phi$, the Nef-induced weak signaling activation in $\mathrm{M} 1-\mathrm{M} \Phi$ was also TAK1 dependent.

TAK1 inhibitor diminishes Nef-induced M2- to M1-like $\mathbf{M} \Phi$ differentiation. We next investigated whether 5Z-7oxozeaenol also inhibits the phenotypic alterations induced by Nef in $\mathrm{M} 2-\mathrm{M} \Phi$. To this end, we focused on the expression of the scavenger receptor CD163 and the production of IL-6, because Nef downregulated CD163 in M2-M $\Phi$ but induced their production of a number of pro-inflammatory cytokines and chemokines, including IL-6. ${ }^{14}$ As shown in Figure $4 \mathrm{a}$, 5Z-7-oxozeaenol $(0.3 \mu \mathrm{M})$ diminished the downregulation of CD163 induced by wild-type (WT) Nef or the LL/AA Nef mutant. Moreover, 5Z-7-oxozeaenol $(0.3 \mu \mathrm{M})$ strongly inhibited the Nef-induced production of IL-6 (Figure 4b). Consistent with the ability to activate signaling (see Figure 1b), the LL/AA Nef mutant, but not the G2A and AxxA mutants, strongly induced IL- 6 production, and the LL/AA-induced IL- 6 production was also inhibited by $5 Z-7-$ oxozeaenol (Figure 4c). WT and the LL/AA mutant did not affect the level of IFN- $\gamma$ and IL-12 (data not shown) but strongly induced the production of TNF- $\alpha$ and slightly induced the production of IL-10, which were also inhibited by $5 Z-7$ oxozeaenol (Figure 4d).

We also investigated whether the higher concentration of Nef stimulates the production of cytokines and chemokines in $\mathrm{M} 1-\mathrm{M} \Phi$ as was observed in $\mathrm{M} 2-\mathrm{M} \Phi^{14}$ and whether $5 \mathrm{Z}-7-$ oxozeaenol inhibits this process. Indeed, when used at $1000 \mathrm{ng} / \mathrm{ml}$, Nef enhanced the production of I-309, GRO $\alpha$, IL-1ra (IL-1 receptor antagonist), IL-6, and IL-8 even in M1$\mathrm{M} \Phi$, which was markedly inhibited by $0.3 \mu \mathrm{M} 5 \mathrm{Z}-7$-oxozeaenol (Figure $4 \mathrm{e}$ ). These results clearly indicate that the Nefinduced signaling activation and phenotypic alterations are mediated by TAK1, in both $\mathrm{M} 2$ and $\mathrm{M} 1-\mathrm{M} \Phi$.

\section{Dominant-negative (DN) TAK1 mutant diminishes Nef-induced signaling activation and phenotypic} alterations. To further verify the importance of TAK1 in Nef-induced aberrant $\mathrm{M} \Phi$ differentiation, we next performed experiments with a catalytically inactive DN form of TAK1, which carries a K63W substitution in its ATP-binding site. ${ }^{24}$ A RING domain-deleted DN form of TRAF2 (TNF receptorassociated factor 2), which lacks E3 ligase activity, was also used, as TRAF2 functions as an upstream signaling molecule of TAK1. ${ }^{23}$ Mouse M $\Phi$-like RAW264.7 cells were used as target cells, because soluble Nef induced the activation of p38 and JNK and the degradation of $\mathrm{I}_{\kappa} \mathrm{B}$ in the cells (Figure $5 \mathrm{a}$ ), as was observed in human primary $\mathrm{M} 2-\mathrm{M} \Phi$. The $\mathrm{p} 38$ and JNK activation and $I_{\kappa} \mathrm{B}$ degradation induced by Nef in RAW264.7 cells were also inhibited by 5Z-7oxozeaenol (data not shown). As shown in Figures $5 a$ and b, 
a

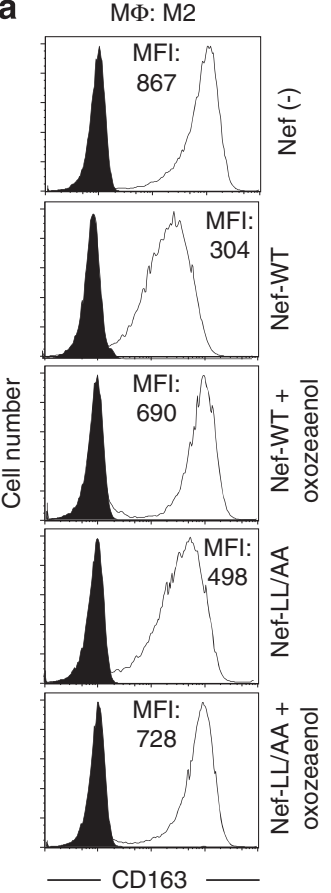

b

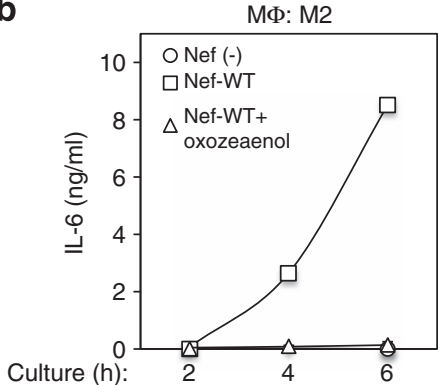

c

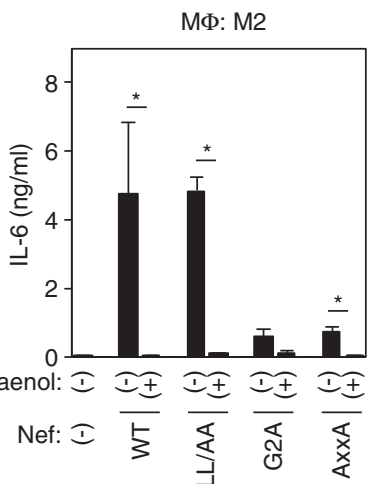

d

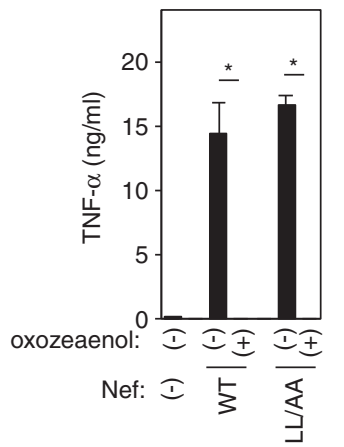

MФ: M2

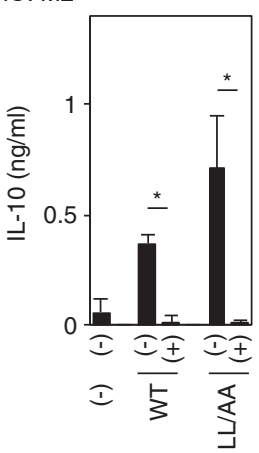

e

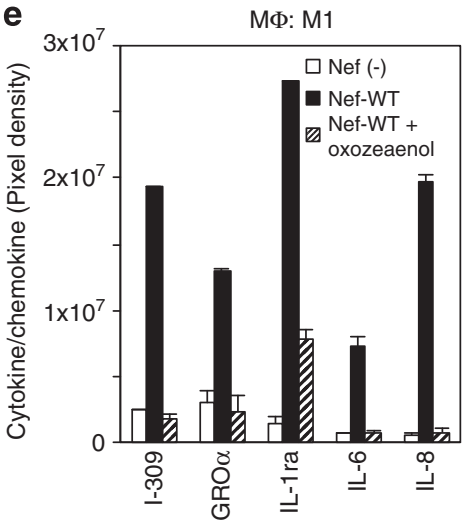

Figure 4 The effects of 5Z-7-oxozeaenol on the Nef-induced downregulation of CD163 and production of interleukin (IL)-6 in M2-M $\Phi$, and the Nef-induced enhancement of cytokines and chemokines production in M1-M $\Phi$. (a) Macrophages colony-stimulating factor (M-CSF)-derived M2-M $\Phi$ were pretreated for $1 \mathrm{~h}$ with DMSO or $0.3 \mu \mathrm{M} 5 \mathrm{Z}-7$ oxozeaenol. Then, the M2-M $\Phi$ were left untreated or stimulated with $100 \mathrm{ng} / \mathrm{ml}$ WT Nef or the LL/AA mutant for $4 \mathrm{~h}$ and then analyzed for their surface expression of CD163 by flow cytometry. Mean fluorescence intensity (MFI) values are shown. The experiments were repeated with $\mathrm{M} \Phi$ obtained from different donors, and the data shown are representative of three independent experiments with similar results. (b) M2-M $\Phi$ were pretreated for $1 \mathrm{~h}$ with DMSO or $0.3 \mu \mathrm{M} 5 \mathrm{Z}-7-\mathrm{oxozeaenol}$. Then, the M2-M $\Phi$ were left untreated or stimulated with $100 \mathrm{ng} / \mathrm{ml} \mathrm{WT}$ Nef for 2,4 , or $6 \mathrm{~h}$. The concentrations of IL-6 in the M $\Phi$ supernatants were analyzed by enzyme-linked immunosorbent assay. Results are expressed as the mean \pm S.D. of triplicate assays. (c and d) M2-M $\Phi$ were pretreated for $1 \mathrm{~h}$ with DMSO or $0.3 \mu \mathrm{M} 5 \mathrm{Z}-7-0 \times 0 z$-aenol. Then, the M2-M $\Phi$ were stimulated with $100 \mathrm{ng} / \mathrm{ml} \mathrm{WT}$ Nef or the indicated Nef mutants for $4 \mathrm{~h}$, and the concentrations of IL-6 (c), tumor necrosis factor (TNF)- $\alpha$ (d) or IL-10 (d) in the M $\Phi$ supernatants were analyzed by enzyme-linked immunosorbent assay. The results for $M \Phi$ obtained from three different donors are summarized. ${ }^{*} P<0.05$. (e) Granulocyte-macrophages colony-stimulating factor-derived $\mathrm{M} 1-\mathrm{M} \Phi$ were pretreated for $1 \mathrm{~h}$ with $\mathrm{DMSO}$ or $0.3 \mu \mathrm{M} 5 \mathrm{Z}-7-0 x$ zozeaenol. Then, the M1-M $\Phi$ were left untreated or stimulated with $1000 \mathrm{ng} / \mathrm{ml}$ WT Nef for 2 days. The relative concentrations of various cytokines and chemokines in the $M \Phi$ supernatants were analyzed using a human cytokine array. The culture supernatants collected after centrifugation $(100 \mu \mathrm{l})$ were added to blots onto which the capture antibodies had been spotted in duplicate. After incubation with the secondary antibody mixture, the signals were detected using the western blotting detection reagent. The data shown in the bar graph were derived from densitometric analyses of selected targets that showed elevated levels in the presence of Nef and are representative of two independent experiments with similar results

the ectopic expression of the DN form of TAK1 or TRAF2 diminished the p38 and JNK activation and $\mathrm{I} \kappa \mathrm{B}$ degradation induced by Nef in RAW264.7 cells. We previously demonstrated that Nef downregulated the cell surface expression of $\mathrm{M}-\mathrm{CSF}$ receptor in human $\mathrm{M} 2-\mathrm{M} \Phi,{ }^{14}$ which is an essential signaling axis for the maintenance of anti-inflammatory phenotypes of $\mathrm{M} \Phi .^{15-17}$ Importantly, the ectopic expression of the DN TAK1 mutant in RAW264.7 cells also diminished the Nef-induced downregulation of M-CSF receptor expression (Figures $5 c$ and $d$ ).

Efficient internalization of Nef into $M 2-M \Phi$ is mediated by higher macropinocytosis activity of M2-M $\Phi$. Finally, we attempted to clarify the molecular mechanism by which Nef enters $\mathrm{M} \Phi$, by taking advantage of the finding that Nef enters $\mathrm{M} 2-\mathrm{M} \Phi$ more efficiently than $\mathrm{M} 1-\mathrm{M} \Phi$ and IL-32-treated 


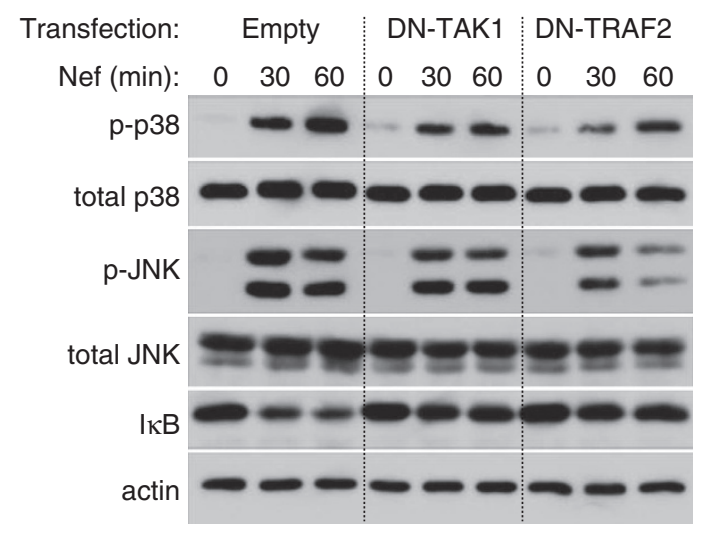

C

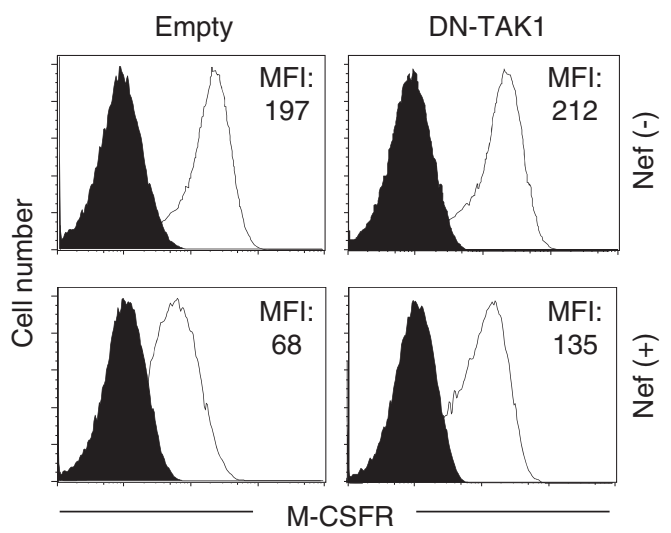

d

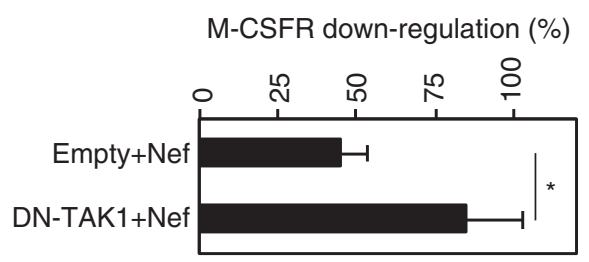

b

O Empty

$\square$ DN-TAK1

$\triangle$ DN-TRAF2
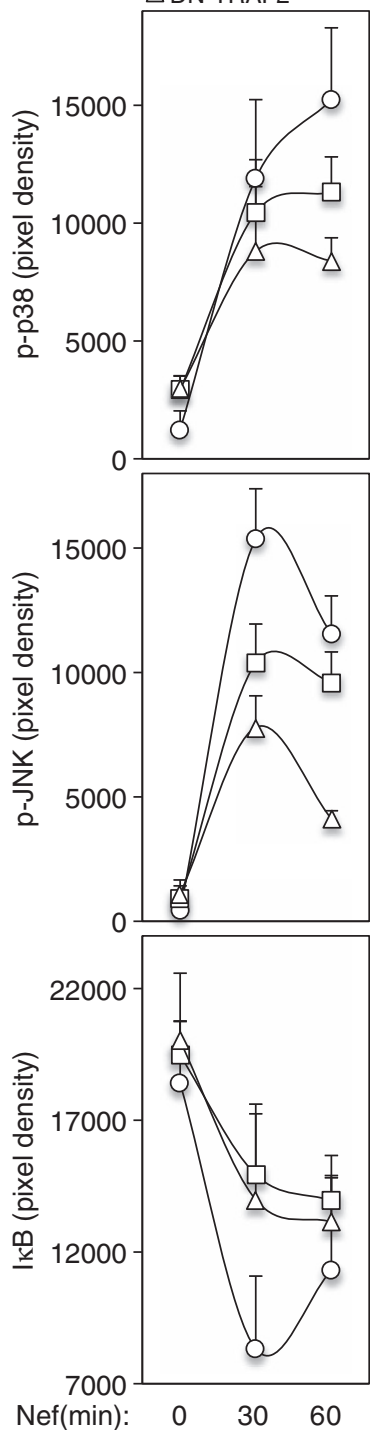

Figure 5 The effect of ectopic expression of the DN TAK1 or TRAF2 mutant on Nef-induced signaling activation and macrophages colony-stimulating factor receptor (M-CSFR) downregulation in RAW264.7 cells. (a and $\mathbf{b})$ RAW264.7 cells transfected with the empty vector (Empty) or the DN TAK1 or TRAF2 mutant were stimulated with Nef $(100 \mathrm{ng} / \mathrm{ml})$ for the indicated periods $(\mathrm{min})$ and then analyzed by western blotting using the indicated antibodies. The data shown in the bar graphs are derived from densitometric analyses obtained from three independent experiments. (c and d) RAW264.7 cells transfected with the empty vector (Empty) or the DN TAK1 mutant were left untreated (upper panels) or stimulated with $100 \mathrm{ng} / \mathrm{ml}$ Nef (lower panels) for 2 days and then analyzed for their surface expression of M-CSFR by flow cytometry. Mean fluorescence intensity (MFI) values are shown. In the bar graph, the MFI values of the Nef-treated cells are represented as percentages relative to the MFI values of the untreated cells, and the data shown are derived from three independent experiments. ${ }^{*} P<0.05$. JNK, c-Jun $\mathrm{N}$-terminal kinase

$\mathrm{M} 2-\mathrm{M} \Phi$ (see Figure 3). Dynasore, which is a potent inhibitor of endocytic pathways known to depend on a large GTPase dynamin, ${ }^{33}$ had little effect on the internalization of FITClabeled Nef into $\mathrm{M} 2-\mathrm{M} \Phi$ (Figures $6 \mathrm{a}$ and b). Of importance, however, we found that EIPA (5-( $N$-ethyl- $N$-isopropyl)amiloride), which is a potent and specific inhibitor of $\mathrm{Na}^{+} / \mathrm{H}^{+}$ exchanger activity important for macropinosome formation, ${ }^{34,35}$ significantly inhibited the Nef internalization into $\mathrm{M} 2-\mathrm{M} \Phi$ (Figures $6 \mathrm{a}$ and $\mathrm{b}$ ). Indeed, when assessed by the uptake of lucifer yellow, a fluorescent dye commonly used to monitor macropinocytosis, ${ }^{36}$ the macropinocytosis activity of
$\mathrm{M} 2-\mathrm{M} \Phi$ was higher than that of $\mathrm{M} 1-\mathrm{M} \Phi$ (Figures $6 \mathrm{c}$ and $\mathrm{d}$ ). Moreover, IL-32-treated M2-M $\Phi$, into which Nef entered less efficiently (see Figure 3a), showed a weaker macropinocytosis activity than untreated $\mathrm{M} 2-\mathrm{M} \Phi$ (Figures $6 \mathrm{c}$ and $\mathrm{d}$ ). These results strongly suggested that Nef entered M2-MФ efficiently by exploiting their higher macropinocytosis activity.

In summary, the current study identified the whole pathway by which Nef induces the M2 to M1-like M $\Phi$ differentiation; Nef enters $M 2-M \Phi$ efficiently by exploiting their intrinsic higher macropinocytosis activity and drives them towards M1-like $\mathrm{M} \Phi$ by activating a signaling cascade that includes TAK1. 
a

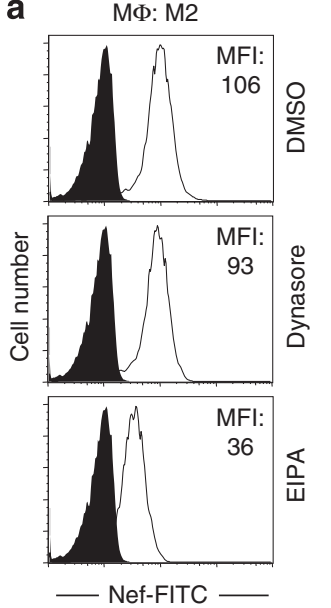

C
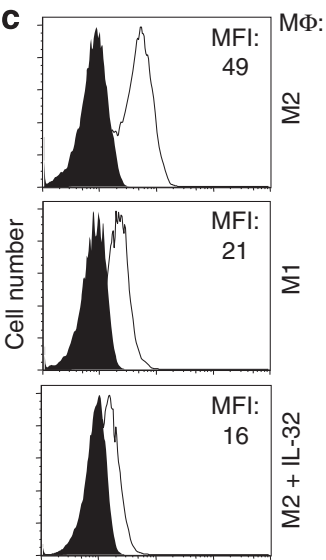

- lucifer yellow - b

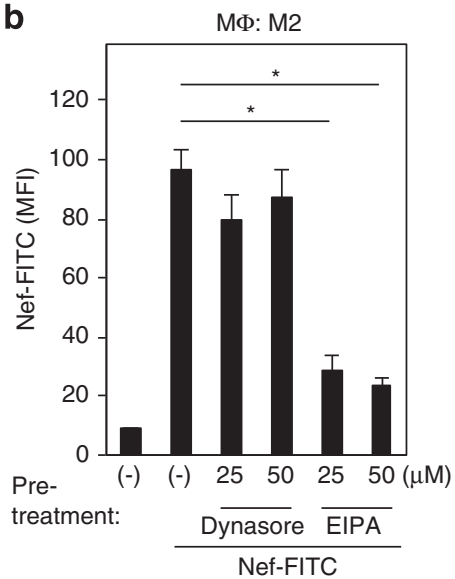

d

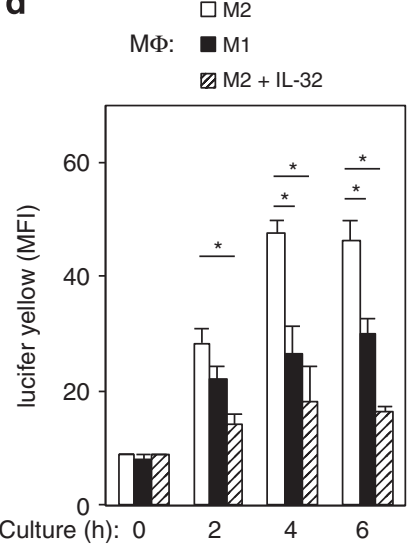

Figure 6 The effect of Dynasore or EIPA on the internalization of Nef into $\mathrm{M} 2-\mathrm{M} \Phi$, and macropinocytosis activity of $\mathrm{M} 2-\mathrm{M} \Phi, \mathrm{M} 1-\mathrm{M} \Phi$, and interleukin (IL)-32treated $\mathrm{M} 2-\mathrm{M} \Phi$. (a) Macrophages colony-stimulating factor-derived $\mathrm{M} 2-\mathrm{M} \Phi$ were pretreated for $30 \mathrm{~min}$ with DMSO or $25 \mu \mathrm{M}$ Dynasore or EIPA. Then, the M $\Phi$ were incubated with FITC (fluorescein isothiocyanate)-labeled Nef $(100 \mathrm{ng} / \mathrm{ml})$ for $60 \mathrm{~min}$ at $37^{\circ} \mathrm{C}$, detached from the wells using trypsin after extensive washing with phosphate-buffered saline (PBS), and analyzed for internalized Nef by flow cytometry. Mean fluorescence intensity (MFI) values are shown. (b) M2-M $\Phi$ were pretreated for $30 \mathrm{~min}$ with DMSO or Dynasore or EIPA at the concentrations indicated $(\mu \mathrm{M})$. Then, the $\mathrm{M} \Phi$ were incubated with FITC-labeled Nef $(100 \mathrm{ng} / \mathrm{ml})$ for $60 \mathrm{~min}$ at $37^{\circ} \mathrm{C}$ and analyzed as in panel (a). The results for $M \Phi$ obtained from three different donors are summarized. ${ }^{*} P<0.05$. (c) $\mathrm{M} 2-\mathrm{M} \Phi, \mathrm{M} 1-\mathrm{M} \Phi$, and IL-32treated M2-M $\Phi$ were incubated with $100 \mu \mathrm{g} / \mathrm{ml}$ lucifer yellow for $4 \mathrm{~h}$, detached from the wells using trypsin after extensive washing with PBS, and analyzed for their uptake of the dye. MFI values are shown. (d) M2-M $\Phi, \mathrm{M} 1-\mathrm{M} \Phi$, and IL-32-treated $\mathrm{M} 2-\mathrm{M} \Phi$ were incubated with $100 \mu \mathrm{g} / \mathrm{ml}$ lucifer yellow for 2,4, or $6 \mathrm{~h}$, and analyzed as in panel (c). The results for $M \Phi$ obtained from three different donors are summarized. ${ }^{*} P<0.05$

\section{Discussion}

M-CSF and GM-CSF support the differentiation and survival of $\mathrm{M} \Phi .{ }^{17}$ Other cytokines such as IL-34 and IL-32 also have been shown to support $\mathrm{M} \Phi$ differentiation and survival. ${ }^{32,37,38}$ Among them, M-CSF is the most critical, because the development of most tissue $M \Phi$ depends on M-CSF, as demonstrated by studies with mice, such as M-CSF-deficient op/op, ${ }^{18} \mathrm{M}$-CSF receptor knockout, ${ }^{19}$ and GM-CSF knockout mice. $^{39}$ Thus, our previous finding that HIV-1 Nef preferentially targets M-CSF-derived M2-M $\Phi$, which predominate under normal conditions, and drives them towards M1-like $M \Phi$ provides a novel mechanism by which HIV-1 efficiently and rapidly induces the sustained immune activation observed in HIV-1 infection. A noteworthy finding of the present study is that Nef enters $\mathrm{M} 2-\mathrm{M} \Phi$ by exploiting their intrinsic higher macropinocytosis activity (Figure 6). It has been shown that Nef directly enters $M \Phi$, induces signaling activation, and accumulates in perinuclear regions. ${ }^{8,14,31}$ However, how Nef enters $\mathrm{M} \Phi$ was poorly understood. Macropinocytosis is responsible for nonspecific uptake of fluid, solutes, membranes, ligands, and small particles attached to the plasma membranes and is regulated by the activation of receptor tyrosine kinases, which occurs in response to growth factors, including M-CSF ${ }^{40}$ Indeed, EIPA, which has been shown to inhibit macropinosome formation without affecting other endocytic pathways, ${ }^{41}$ significantly inhibited the Nef internalization into $\mathrm{M} 2-\mathrm{M} \Phi$ (Figures $6 \mathrm{a}$ and b). Dynasore, the potent inhibitor of endocytic pathways known to depend on a large GTPase dynamin, ${ }^{33}$ had little effect on the internalization of Nef into $\mathrm{M} 2-\mathrm{M} \Phi$ (Figures $6 \mathrm{a}$ and $\mathrm{b}$ ). The finding that the macropinocytosis activity of $\mathrm{M} 1-\mathrm{M} \Phi$ and IL-32-treated $\mathrm{M} 2-\mathrm{M} \Phi$, into which Nef entered less efficiently (Figures $3 a$ and $c$ ), was weaker than that of $\mathrm{M} 2-\mathrm{M} \Phi$ (Figures $6 \mathrm{c}$ and $\mathrm{d}$ ) further supports the idea that Nef exploits macropinocytosis to enter $\mathrm{M} \Phi$.

Recent studies show that macropinocytosis is used by many biological processes. For instance, Ras-transformed cells use macropinocytosis to transport extracellular proteins into the cells for their metabolic needs. ${ }^{42}$ Interestingly, macropinocytosis is also used by a variety of non-enveloped and enveloped viruses, including HIV-1, for their entry into the target cells. ${ }^{34,35,43,44}$ More interestingly, it was shown that the HIV-1 trans-activating protein Tat enters cells by macropinocytosis. ${ }^{45}$ Thus, our finding that Nef exploits macropinocytosis to enter $M 2-M \Phi$ efficiently further strengthens the important role of macropinocytosis in the pathogenesis of HIV-1.

Another noteworthy finding of the present study is that Nef induces the $\mathrm{M} 2$ - to $\mathrm{M} 1$-like $\mathrm{M} \Phi$ differentiation through the activation of TAK1, which was confirmed by the experiments with 5Z-7-oxozeaenol, the selective inhibitor of TAK1 (Figures 2 and 4), and those with the DN form of TAK1 (Figure 5). It has been shown that other viruses also hijack the TAK1 cascade. For instance, TAK1 was found to be constitutively activated in HTLV-1-infected T lymphoma cell lines in a viral Tax oncoprotein-dependent manner. ${ }^{46}$ EB virus-encoded latent membrane protein 1 can also activate TAK $1 .{ }^{47}$ Interestingly, it was recently demonstrated that the HIV-1 glycoprotein gp41 activated NF- $\kappa$ B pathway in a TAK1-dependent manner to potentiate viral replication in $\mathrm{CD}^{+}{ }^{+} \mathrm{T}_{\text {cells. }}{ }^{48}$ It was also recently demonstrated that BST2 (also known as tetherin), a cellular protein that inhibits HIV-1 virion release by physically tethering virions to the cell surface, was able to induce proinflammatory signaling in CD4 ${ }^{+}$T cells in a TAK1-dependent manner, when it restricted virion release. ${ }^{49,50}$ Another cellular HIV-1 restriction protein, TRIM5, was also reported to activate TAK1 when it interacted with the viral capsid lattice. ${ }^{51}$ Thus, our finding that Nef also utilizes TAK1 to activate and drive anti-inflammatory $\mathrm{M} 2-\mathrm{M} \Phi$ towards an inflammatory $\mathrm{M} 1$-like 
phenotypic differentiation further strengthens the assertion that TAK1 have a multifaceted role in the pathogenesis of HIV-1.

Mechanistically, Nef appears to activate TAK1 through TRAF2, the upstream molecule of TAK $1,{ }^{23}$ because the DN TRAF2 mutant diminished the Nef-induced p38 and JNK activation and $\mathrm{I} \kappa \mathrm{B}$ degradation (Figures $5 \mathrm{a}$ and $\mathrm{b}$ ), as well as the Nef-induced downregulation of M-CSF receptor expression (data not shown). These results were consistent with the recent finding that Nef interacts with TRAF2. ${ }^{52,53}$ Interestingly, the N-terminal acidic cluster domain of Nef mediates its interaction with TRAF2. ${ }^{52}$ Thus, further studies are necessary to clarify why the AxxA mutant, which carries a mutation in another motif adjacent to the acidic cluster domain, ${ }^{26}$ that is, the proline-rich PxxP motif, failed to activate MAP kinases, NF- $\kappa$ B pathway, and TAK1 (Figure 1b).

HIV-1 infection leads to chronic inflammation and alterations in the levels of pro-inflammatory cytokines, including IL- $6 .{ }^{54}$ In this study, we showed that Nef strongly induced the production of IL-6 in M2-M $\Phi$, which was blocked by the TAK1 inhibitor (Figures $4 \mathrm{~b}$ and $\mathrm{c}$ ). We also found that Nef induced a sustained induction of IL- 6 in M2-M $\Phi$ even when monitored up to day 9 (data not shown). Importantly, several cohort studies have revealed that the increased level of IL- 6 is associated with HIV1 disease progression risk and an all-cause mortality in chronic HIV-1 infection. ${ }^{54-58}$ However, the drivers of IL-6 production in HIV-1 infection are not known. Thus, our finding raises an intriguing possibility that the $\mathrm{M} 1$-like $\mathrm{M} \Phi$ differentiated from $\mathrm{M} 2$ $M \Phi$ by the action of Nef are a source of IL- 6 in HIV- 1 infection. The identified whole pathway by which Nef induces the M2- to $M 1-l i k e \mathrm{M} \Phi$ differentiation will contribute to novel therapies to prevent or reverse inflammation in HIV-1-infected patients.

\begin{abstract}
Materials and Methods
Recombinant Nef proteins and cytokines. C-terminally His-tagged 210-amino acid HIV-1 Nef proteins (SF2 strain) produced in E. coli were purchased from Jena Bioscience (Jena, Germany). In selected experiments (Figure 1b, Figures $4 a$ and c), Nef mutants (G2A, AxxA, or LL/AA; see Figure 1b for details) purchased from Jena Bioscience were also used. The endotoxin level of these preparations was $<0.3 \mathrm{EU}$ per $1 \mu \mathrm{g}$ as determined by the LAL method (data not shown). Recombinant human (rh)M-CSF with a molecular weight of $85 \mathrm{kDa}^{59}$ was a gift from Morinaga Milk Industry (Kanagawa, Japan). rhGM-CSF and rhTNF- $\alpha$ were purchased from PeproTech (Rocky Hill, NJ, USA). rhIL-32 $\gamma$ was purchased from R\&D Systems (Minneapolis, MN, USA).
\end{abstract}

Chemical inhibitors. The resorcylic acid lactone 5Z-7-oxozeaenol, which is the selective inhibitor of TAK1, ${ }^{29,30}$ was purchased from Calbiochem (Gibbstown, $\mathrm{NJ}$, USA). Dynasore, the potent inhibitor of endocytic pathways known to depend on a large GTPase dynamin, ${ }^{33}$ and EIPA, the potent and specific inhibitor of $\mathrm{Na}^{+} / \mathrm{H}^{+}$exchanger activity important for macropinosome formation, ${ }^{34,35}$ were purchased from Sigma (St. Louis, MO, USA). These inhibitors were dissolved in dimethyl sulfoxide (DMSO; Wako, Osaka, Japan) and added to the culture of $M \Phi$ cultures before their stimulation with $\mathrm{Nef}$ at the indicated concentrations $(0.1 \%$ $\mathrm{v} / \mathrm{v})$. The same volume of DMSO was used as a vehicle control.

Preparation of primary human monocyte-derived $\mathbf{M} \Phi$. Heparinized venous blood was collected from healthy donors after informed consent had been obtained in accordance with the Declaration of Helsinki. The approval for this study was obtained from the Kumamoto University medical ethical committee. $\mathrm{M} \Phi$ were prepared essentially as described previously. ${ }^{14}$ Briefly, mononuclear cells obtained using PANCOLL reagent (PAN Biotech, Aidenbach, Germany) were suspended in RPMl1640 medium-1\% FCS at a density of $1 \times 10^{6}$ cells/ml and seeded in multiwell plates or dishes. Monocytes were enriched by allowing the cells to adhere to the plates or dishes for $1 \mathrm{~h}$ at $37^{\circ} \mathrm{C}$, and non-adherent cells were removed by extensive washing with PBS. Then, the adherent monocytes were differentiated into $M \Phi$ by culturing them with RPMl1640-10\% FCS containing $100 \mathrm{ng} / \mathrm{ml}$ rhM-CSF $(\mathrm{M} 2-\mathrm{M} \Phi)$ or $10 \mathrm{ng} / \mathrm{ml}$ rhGM-CSF $(\mathrm{M} 1-\mathrm{M} \Phi)$. After 3 days, the cultures were replaced with fresh complete media after extensive washing with PBS to remove non-adherent cells, before being incubated for another 2 days. At day 5 , the purity of the $M \Phi$ prepared by this method was routinely $>95 \%$, according to a flow cytometric analysis of CD14 expression (data not shown). In selected experiments (Figures $3 a$ and $b$, and $6 c$ and d), rhlL-32 $\gamma$ was added to the M-CSF-derived day- $5 \mathrm{M} \Phi$ at a final concentration of $100 \mathrm{ng} / \mathrm{ml}$, and the $\mathrm{M} \Phi$ were cultured for another 2 days. The differentiated $M \Phi$ were used in the subsequent experiments. Recombinant Nef was added at a final concentration of $100 \mathrm{ng} / \mathrm{ml}$, unless otherwise stated.

RAW264.7 cells, DN TAK1 and TRAF2 and transfection. In this study, we also used mouse $M \Phi$ cell line RAW264.7, which was obtained from RIKEN Cell Bank (Tsukuba, Japan) and maintained in RPMl1640-10\% FCS. The Flag-tagged DN mutants of mouse TAK1 (K63W) and TRAF2 (257-501), which were cloned in pcDNA3 vector (Invitrogen, Carlsbad, CA, USA), were provided by Ito $\mathrm{M}^{60}$ Transient expression of the DN TAK1 or TRAF2 in RAW264.7 cells was performed using X-tremeGENE HP reagent (Roche, Indianapolis, IN, USA), according to the manufacturer's recommendations. Briefly, the cells were seeded in a 12-well tissue culture plate $\left(2 \times 10^{5}\right.$ cells/well), transfected with $2 \mu \mathrm{g}$ plasmid (the empty vector or the DN TAK1 or TRAF2 plasmid) and $4 \mu$ of the transfection reagent, and cultured for 2 days. The transfected RAW264.7 cells were used in subsequent experiments.

Western blotting. Western blotting was performed essentially as described previously. ${ }^{14}$ Briefly, the cells were stimulated and lysed on ice with Nonidet P-40 lysis buffer ( $1 \%$ Nonidet P-40, $50 \mathrm{mM}$ Tris, and $150 \mathrm{mM} \mathrm{NaCl}$ ) containing protease inhibitors ( $1 \mathrm{mM}$ EDTA, $1 \mu \mathrm{M}$ PMSF, $1 \mu \mathrm{g} / \mathrm{ml}$ aprotinin, $1 \mu \mathrm{g} / \mathrm{ml}$ leupeptin, and $1 \mu \mathrm{g} / \mathrm{ml}$ pepstatin) and phosphatase inhibitors ( $1 \mathrm{mM} \mathrm{Na}_{3} \mathrm{VO}_{4}$ and $\left.1 \mathrm{mM} \mathrm{NaF}\right)$. The resultant total cell lysates were then subjected to western blotting. The antibodies used were as follows: anti-phospho-specific p38 (Thr180/Tyr182; Cell Signaling, Danvers, MA, USA), anti-p38 (no. A-12; Santa Cruz Biotechnology, Dallas, TX, USA), anti-phospho-specific JNK (Thr183/Tyr185; Cell Signaling), anti-JNK (no. FL; Santa Cruz Biotechnology), anti-phospho-specific ERK (Tyr204; Santa Cruz Biotechnology), anti-ERK (no. K-23; Santa Cruz Biotechnology), anti- $\mid \kappa B-\alpha$ (no. C-21; Santa Cruz Biotechnology), anti-phospho-specific IKK $\alpha / \beta$ (Ser176/Ser180; Cell Signaling), anti-IKK $\alpha$ (no. 2682; Cell Signaling), anti-phospho-specific TAK1 (Thr184/Thr187; Cell Signaling), anti-TAK1 (no. 4505; Cell Signaling), antiphospho-specific Stat1 (pY701; BD Biosciences, San Jose, CA, USA), anti-Stat1 (no. 610185; BD Biosciences), anti-phospho-specific Stat3 (pY705; BD Biosciences), anti-Stat3 (no. 610189; BD Biosciences), anti-phospho-specific Stat5 (pY694; BD Biosciences), anti-Stat5 (no. 610191; BD Biosciences), and antiactin (no. C-2; Santa Cruz Biotechnology). Detection was performed with HRPlabeled secondary antibodies (GE Healthcare, Pittburgh, PA, USA), the Immunostar LD western blotting detection reagent (Wako), and an image analyzer ImageQuant LAS 4000 (GE Healthcare). In a selected experiment (Figure $5 b$ ), the intensity of the bands was quantified using the ImageQuant TL software (GE Healthcare).

Flow cytometry. The internalization of Nef into $M \Phi$ was quantified by flow cytometry on an LSR II (BD Biosciences) using the FlowJo software (Tree Star, Ashland, OR, USA). M $\Phi$ were incubated with FITC-labeled Nef (purchased from Fitzgerald, Acton, MA, USA) at $37^{\circ} \mathrm{C}$, detached from the wells using $0.25 \%$ trypsin (Wako) after extensive washing with PBS, and immediately subjected to flow cytometric analysis. ${ }^{14}$ The macropinocytosis activity of $M \Phi$ was analyzed by measuring the uptake of lucifer yellow. ${ }^{36} M \Phi$ were incubated with lucifer yellow $\mathrm{CH}$ dipotassium salt (Sigma; $100 \mu \mathrm{g} / \mathrm{ml}$ ) for 2, 4 , or $6 \mathrm{~h}$, detached from the wells using $0.25 \%$ trypsin after extensive washing with PBS, and immediately subjected to flow cytometric analysis. The surface expression of CD163 on M $\Phi$ and M-CSF receptor on RAW264.7 cells was also assessed by flow cytometry. Cells left untreated or stimulated with Nef were detached from the wells using enzyme-free cell dissociation buffer (Gibco, Grand Island, NY, USA), stained with PE-labeled anti-human CD163 (GHI/61; BioLegend, San Diego, CA, USA), or PE-labeled anti-mouse M-CSF receptor (AFS98; eBioscience, San Diego, CA, USA) and analyzed on the LSR II using the FlowJo software.

Cytokine/chemokine production. The supernatants of $\mathrm{M} 2-\mathrm{M} \Phi$ stimulated with Nef were collected and analyzed for the concentration of IL-6, IL-10, 
IL-12/L-23 (p40), IFN- $\gamma$, and TNF- $\alpha$ by ELISA (BioLegend). The relative levels of multiple cytokines and chemokines in the supernatants of $\mathrm{M} 1-\mathrm{M} \Phi$ stimulated with Nef were analyzed using a human cytokine array (R\&D Systems) according to the manufacturer's instructions. Briefly, the culture supernatants of M1-M $\Phi(100 \mu l)$, which were collected after centrifugation, were added to dot blots onto which the capture antibodies had been spotted in duplicate. After incubation with the secondary antibody mixture, the signals were detected using the Immunostar LD western blotting detection reagent and an ImageQuant LAS 4000 image analyzer. ${ }^{14}$ The intensity of the spots was quantified using the ImageQuant TL software.

Statistical analysis. The statistical significance of inter-sample differences was determined using the Student's $t$-test. $P$-values of $<0.05$ were considered significant.

\section{Conflict of Interest}

The authors declare no conflict of interest.

Acknowledgements. We thank Yuriko Matsunaga and Noriko Tokushige for secretarial assistance. This study was supported by a grant from the Ministry of Education, Culture, Sports, Science, and Technology of Japan (to SS). This study was also supported by the Global COE program 'Global Education and Research Center Aiming at the Control of AIDS', which was commissioned by the Ministry of Education, Culture, Sports, Science, and Technology of Japan (to SS).

1. Wynn TA, Chawla A, Pollard JW. Macrophage biology in development, homeostasis and disease. Nature 2013; 496: 445-455.

2. Sica A, Mantovani A. Macrophage plasticity and polarization: in vivo veritas. J Clin Invest 2012; 122: 787-795.

3. Deeks SG, Walker BD. The immune response to AIDS virus infection: good, bad, or both? $J$ Clin Invest 2004; 113: 808-810.

4. Appay V, Sauce D. Immune activation and inflammation in HIV-1 infection: causes and consequences. J Pathol 2008; 214: 231-241.

5. Porcheray F, Samah B, Leone C, Dereuddre-Bosquet N, Gras G. Macrophage activation and human immunodeficiency virus infection: HIV replication directs macrophages towards a pro-inflammatory phenotype while previous activation modulates macrophage susceptibility to infection and viral production. Virology 2006; 349: 112-120.

6. Brown JN, Kohler JJ, Coberley CR, Sleasman JW, Goodenow MM. HIV-1 activates macrophages independent of Toll-like receptors. PLoS One 2008; 3: e3664.

7. Cassol E, Cassetta L, Alfano M, Poli G. Macrophage polarization and HIV-1 infection. $J$ Leukoc Biol 2010; 87: 599-608.

8. Herbein G, Gras G, Khan KA, Abbas W. Macrophage signaling in HIV-1 infection. Retrovirology 2010; 7: 34

9. Fujii Y, Otake K, Tashiro M, Adachi A. Soluble Nef antigen of HIV-1 is cytotoxic for human CD4 ${ }^{+} \mathrm{T}$ cells. FEBS Lett 1996; 393: 93-96.

10. Federico M, Percario Z, Olivetta E, Fiorucci G, Muratori C, Micheli A et al. HIV-1 Nef activates STAT1 in human monocytes/macrophages through the release of soluble factors. Blood 2001; 98: 2752-2761.

11. Varin A, Manna SK, Quivy V, Decrion AZ, Van Lint C, Herbein G et al. Exogenous Nef protein activates NF- $\kappa \mathrm{B}, \mathrm{AP}-1$, and $\mathrm{c}$-Jun N-terminal kinase and stimulates HIV transcription in promonocytic cells. Role in AIDS pathogenesis. J Biol Chem 2003; 278 : 2219-2227.

12. Olivetta E, Percario Z, Fiorucci G, Mattia G, Schiavoni I, Dennis $C$ et al. HIV-1 Nef induces the release of inflammatory factors from human monocyte/macrophages: involvement of Nef endocytotic signals and NF- $\kappa$ B activation. J Immunol 2003; 170: 1716-1727.

13. Mangino G, Percario ZA, Fiorucci G, Vaccari G. Manrique S, Romeo $G$ et al. In vitro treatment of human monocytes/macrophages with myristoylated recombinant Nef of human immunodeficiency virus type 1 leads to the activation of mitogen-activated protein kinases, $1 \kappa B$ kinases, and interferon regulatory factor 3 and to the release of beta interferon. J Virol 2007; 81: 2777-2791.

14. Chihara T, Hashimoto M, Osman A, Hiyoshi-Yoshidomi Y, Suzu I, Chutiwitoonchai N et al. HIV-1 proteins preferentially activate anti-inflammatory M2-type macrophages. J Immuno 2012; 188: 3620-3627.

15. Verreck FA, de Boer T, Langenberg DM, Hoeve MA, Kramer M, Vaisberg E. Human IL-23producing type1 macrophages promote but IL-10-produing type 2 macrophages subvert immunity to (myco)bacteria. Proc Natl Acad Sci USA 2004; 101: 4560-4565.

16. Martinez FO, Gordon S, Locati M, Mantovani A. Transcriptional profiling of the human monocyte-to-macrophage differentiation and polarization: new molecules and patterns of gene expression. J Immunol 2006; 177: 7303-7311.

17. Hamilton JA. Colony-stimulating factors in inflammation and autoimmunity. Nat Rev Immunol 2008; 8: 533-544.
18. Ryan GR, Dai XM, Dominguez MG, Tong W, Chuan F, Chisholm 0 et al. Rescue of the colony-stimulating factor 1 (CSF-1)-nullizygous mouse $\left(\mathrm{Csf} 1^{\text {OP }} / \mathrm{Csf} 1^{\circ \mathrm{O}}\right)$ phenotype with a CSF-1 transgene and identification of sites of local CSF-1 synthesis. Blood 2001; 98: 74-84.

19. Dai XM, Ryan GR, Hapel AJ, Dominguez MG, Russell RG, Kapp $S$ et al. Targeted disruption of the mouse colony-stimulating factor 1 receptor gene results in osteopetrosis, mononuclear phagocyte deficiency, increased primitive progenitor cell frequencies, and reproductive defects. Blood 2003; 99: 111-120.

20. Saksela K, Cheng G, Baltimore D. Proline-rich (PxxP) motifs in HIV-1 Nef bind to SH3 domains of a subset of Src kinases and are required for the enhanced growth of $\mathrm{Nef}^{+}$ viruses but not for down-regulation of CD4. EMBO J 1995; 14: 484-491.

21. Dikeakos JD, Atkins KM, Thomas L, Emert-Sedlak L, Byeon IJ, Jung J et al. Small molecule inhibition of HIV-1-induced MHC-I down-regulation identifies a temporally regulated switch in Nef action. Mol Biol Cell 2010; 21: 3279-3292.

22. Krautkramer E, Giese SI, Gasteier JE, Muranyi W, Fackler OT. Human immunodeficiency virus type 1 Nef activates p21-activated kinase via recruitment into lipid rafts. J Virol 2004; 78: 4085-4097.

23. Sakurai $\mathrm{H}$. Targeting of TAK1 in inflammatory disorders and cancer. Trends Pharmacol Sci 2012; 33: 522-530

24. Kishimoto $\mathrm{K}$, Matsumoto $\mathrm{K}$, Ninomiya-Tsuji J. TAK1 mitogen-activated protein kinase kinase kinase is activated by autophosphorylation within its activation loop. J Biol Chem 2000; 275: 7359-7364.

25. Fackler OT, Baur AS. Live and let die: Nef functions beyond HIV replication. Immunity 2002; 16: 493-497.

26. Foster JL, Garcia JV. HIV-1 Nef: at the crossroads. Retrovirology 2008; $5: 84$

27. Yamaguchi K, Shirakabe K, Shibuya H, Irie K, Oishi I, Ueno N et al. Identification of a member of the MAPKKK family as a potential mediator of TGF- $\beta$ signal transduction. Science 1995; 270: 2008-2011.

28. Ninomiya-Tsuji J, Kishimoto K, Hiyama A, Inoue J, Cao Z, Matsumoto K. The kinase TAK1 can activate the NIK-IKB as well as the MAP kinase cascade in the IL-1 signalling pathway. Nature 1999; 398: 252-256.

29. Ninomiya-Tsuji J, Kajino T, Ono K, Ohtomo T, Matsumoto M, Shiina M et al. A resorcylic acid lactone, 5Z-7-oxozeaenol, prevents inflammation by inhibiting the catalytic activity of TAK1 MAPK kinase kinase. J Biol Chem 2003; 278: 18485-18490.

30. Ahmed N, Zeng M, Sinha I, Polin L, Wei WZ, Rathinam C et al. The E3 ligase Itch and deubiquitinase Cyld act together to regulate Tak1 and inflammation. Nat Immunol 2011; 12. 1176-1183.

31. Alessandrini L, Santarcangelo AC, Olivetta E, Ferrantelli F, d'Aloja P, Pugliese K et al. T-tropic human immunodeficiency virus (HIV) type 1 Nef protein enters human monocytemacrophages and induces resistance to HIV replication: a possible mechanism of HIV T-tropic emergence in AIDS. J Gen Virol 2000; 81: 2905-2917.

32. Netea MG, Lewis EC, Azam T, Joosten LA, Jaekal J, Bae SY et al. Interleukin-32 induces the differentiation of monocytes into macrophage-like cells. Proc Natl Acad Sci USA 2008; 105: $3515-3520$

33. Macia E, Ehrlich M, Massol R, Boucrot E, Brunner C, Kirchhausen T. Dynasore, a cell-permeable inhibitor of dynamin. Dev Cell 2006; 10: 839-850.

34. Mercer J, Helenius A. Vaccinia virus uses macropinocytosis and apoptotic mimicry to enter host cells. Science 2008: 320: 531-535.

35. Saeed MF, Kolokoltsov AA, Albrecht T, Davey RA. Cellular entry of ebola virus involves uptake by a macropinocytosis-like mechanism and subsequent trafficking through early and late endosomes. PLOS Pathog 2010; 6: e1001110.

36. Krysko DV, Denecker G, Festjens N, Gabriels S, Parthoens E, D'Herde K et al. Macrophages use different internalization mechanisms to clear apoptotic and necrotic cells. Cell Death Differ 2006; 13: 2011-2022.

37. Lin H, Lee E, Hestir K, Leo C, Huang M, Bosch E et al. Discovery of a cytokine and its receptor by functional screening of the extracellular proteome. Science 2008; 320: 807-811.

38. Chihara T, Suzu S, Hassan R, Chutiwitoonchai N, Hiyoshi M, Motoyoshi K et al. IL-34 and M-CSF share the receptor Fms but are not identical in biological activity and signal activation. Cell Death Differ 2010; 17: 1917-1927.

39. Nilsson SK, Lieschke GK, Garcia-Wijnen CC, Williams B, Tzelepis D, Hodgson G et al. Granulocyte-macrophage colony-stimulating factor is not responsible for the correction of hematopoietic deficiencies in the maturing op/op mouse. Blood 1995; 86: 66-72.

40. Racoosin EL, Swanson JA. M-CSF-induced macropinocytosis increases solute endocytosis but not receptor-mediated endocytosis in mouse macrophages. J Cell Sci 1992; 102: 867-880.

41. Ivanov Al. Pharmacological inhibition of endocytic pathways: is it specific enough to be useful? Methods Mol Biol 2008; 440: 15-33.

42. Commisso C, Davidson SM, Soydaner-Azeloglu RG, Parker SJ, Kamphorst JJ, Hackett S et al. Macropinocytosis of protein is an amino acid supply route in Ras-transformed cells. Nature 2013; 497: 633-637.

43. Mercer J, Helenius A. Gulping rather than sipping: macropinocytosis as a way of virus entry. Curr Opin Microbiol 2012; 15: 490-499.

44. Gobeil LA, Lodge R, Tremblay MJ. Macropinocytosis-like HIV-1 internalization in macrophages is CCR5 dependent and leads to efficient but delayed degradation in endosomal compartments. J Virol 2013; 87: 735-745. 
45. Wadia JS, Stan RV, Dowdy SF. Transducible TAT-HA fusogenic peptide enhances escape of TAT-fusion proteins after lipid raft macropinocytosis. Nat Med 2004; 10: 310-315.

46. Wu X, Sun SC. Retroviral oncoprotein Tax deregulates NF- $\kappa$ B by activating Tak1 and mediating the physical association of Tak1-IKK. EMBO Rep 2007; 8: 510-515.

47. Wu L, Nakano H, Wu Z. The C-terminal activating region 2 of the Epstein-Barr virusencoded latent membrane protein 1 activates NF- $\kappa$ B through TRAF6 and TAK1. J Biol Chem 2006; 281: 2162-2169.

48. Postler TS, Desrosiers RC. The cytoplasmic domain of the HIV-1 glycoprotein gp41 induces NF- $\kappa$ B activation through TGF- $\beta$-activated kinase 1. Cell Host Microbe 2012; 11 : 181-193.

49. Galão RP, Le Tortorec A, Pickering S, Kueck T, Neil SJ. Innate sensing of HIV-1 assembly by Tetherin induces NFKB-dependent proinflammatory responses. Cell Host Microbe 2012; 12: 633-644.

50. Tokarev A, Suarez M, Kwan W, Fitzpatrick K, Singh R, Guatelli J. Stimulation of NF-кB activity by the HIV restriction factor BST2. J Virol 2013; 87: 2046-2057.

51. Pertel T, Hausmann S, Morger D, Züger S, Guerra J, Lascano J et al. TRIM5 is an innate immune sensor for the retrovirus capsid lattice. Nature 2011; 472: 361-365.

52. Mangino G, Percario ZA, Fiorucci G, Vaccari G, Acconcia F, Chiarabelli C et al. HIV-1 Nef induces proinflammatory state in macrophages through its acidic cluster domain: involvement of TNF alpha receptor associated factor 2. PLoS One 2011; 6: e22982.

53. Khan KA, Abbas W, Varin A, Kumar A, Di Martino V, Dichamp I et al. HIV-1 Nef interacts with HCV core, recruits TRAF2, TRAF5 and TRAF6, and stimulates HIV-1 replication in macrophages. J Innate Immun 2013; 5: 639-656.

54. Deeks SG, Tracy R, Douek DC. Systemic effects of inflammation on health during chronic HIV infection. Immunity 2013; 39: 633-645.

55. Kuller LH, Tracy R, Belloso W, De Wit S, Drummond F, Lane HC et al. Inflammatory and coagulation biomarkers and mortality in patients with HIV infection. PLoS Med 2008; 5: e203.
56. Neuhaus J, Jacobs Jr DR, Baker JV, Calmy A, Duprez D, La Rosa A et al. Markers of inflammation, coagulation, and renal function are elevated in adults with HIV infection. $J$ Infect Dis 2010; 201: 1788-1795.

57. Hamlyn E, Fidler S, Stöhr W, Cooper DA, Tambussi G, Schechter M et al. Interleukin-6 and D-dimer levels at seroconversion as predictors of HIV-1 disease progression. AIDS 2014; 201: 1788-1795.

58. Fuster D, Cheng DM, Quinn EK, Armah KA, Saitz R, Freiberg MS et al. Inflammatory cytokines and mortality in a cohort of HIV-infected adults with alcohol problems. AIDS 2014; 28: 1059-1064.

59. Suzu S, Kimura F, Ota J, Motoyoshi K, Itoh T, Mishima $Y$ et al. Biologic activity of proteoglycan macrophage colony-stimulating factor. J Immunol 1997; 159: 1860-1867.

60. Ishizawa YH, Tamura K, Yamaguchi T, Matsumoto K, Komiyama M, Takamatsu N et al. Xenopus death-domain-containing proteins FADD and RIP1 synergistically activate JNK and NF- $\kappa$ B. Biol Cell 2006; 98: 465-478.

(c) (i) $\odot$ Cell Death and Disease is an open-access journal published by Nature Publishing Group. This work is licensed under a Creative Commons Attribution-NonCommercialNoDerivs 3.0 Unported License. The images or other third party material in this article are included in the article's Creative Commons license, unless indicated otherwise in the credit line; if the material is not included under the Creative Commons license, users will need to obtain permission from the license holder to reproduce the material. To view a copy of this license, visit http://creativecommons.org/ licenses/by-nc-nd/3.0/ 